\title{
DYNAMIC RECRYSTALLIZATION BEHAVIOUR OF TWIN ROLL CAST ZAX210 STRIPS DURING HOT DEFORMATION
}

\author{
Kristina KITTNER, Madlen ULLMANN, Thorsten HENSELER, Ulrich PRAHL, Rudolf KAWALLA \\ Technische Universität Bergakademie Freiberg, Institute of Metal Forming, Freiberg, Germany, EU, \\ Madlen.UIImann@imf.tu-freiberg.de
}

https://doi.org/10.37904/metal.2019.930

\begin{abstract}
The recrystallization behaviour of a twin roll cast ZAX210 alloy has been investigated under deformation conditions equivalent to the hot rolling process of magnesium strip. A set of strain levels, beginning at the critical strain for the onset of dynamic recrystallization has been studied. The dynamic recrystallization taking place during hot deformation of the magnesium alloy ZAX210 was analysed by plane strain compression tests together with optical microstructure investigation. The volume fraction and size of dynamically recrystallized grains increased with increasing strain. With equal strain the dynamically recrystallized volume fraction rises with higher deformation temperatures as well as lower strain rates. Furthermore, it has been found that the deformation temperature plays a major role, rather than the strain rates, in the activation of dynamic recrystallization processes during deformation. The results were used to identify the coefficients for the JMAKmodel approach on the dynamic recrystallization of the ZAX210 twin roll cast strip.
\end{abstract}

Keywords: Dynamic recrystallization, magnesium alloy, calcium, Mg-Zn-Al-Ca alloy, twin roll casting, plain strain compression test

\section{INTRODUCTION}

$\mathrm{Mg}-\mathrm{Zn}-\mathrm{Ca}$ alloys are characterized by a refined microstructure as well as improved mechanical properties at elevated temperatures. The addition of calcium leads to the formation of stable intermetallic compounds, such as $\mathrm{Ca}_{2} \mathrm{Mg}_{6} \mathrm{Zn}_{3}$ [1], which contribute to the restriction of grain growth during hot deformation. For Ca-containing magnesium alloys, the main recrystallization mechanisms are reported to be continuous dynamic recrystallization (CDRX) [2,3] and particle stimulated nucleation (PSN) [4-7]. Continuous dynamic recrystallization essentially corresponds to a strong dynamic recovery and predominantly begins at the grain and twin boundaries, as dislocations accumulate and consequently increase the local dislocation density [810]. Low angle grain boundaries (LAGB) are produced by cross slip and climbing of dislocations, with the former being the slowest process of dislocation rearrangement in magnesium alloys [11]. Subsequently, further dislocations are absorbed and low angle grain boundaries transform into high angle grain boundaries (HAGB). PSN is well known to promote recrystallization by large particles acting as nucleation sites. The mechanism of particle stimulated nucleation is mainly influenced by particle size, distance and distribution. In general, small, finely distributed particles $(<1 \mu \mathrm{m})$ impede recrystallization, while large, coarsely distributed particles lead to the acceleration of the recrystallization process $[12,13]$. However, the contribution of PSN to the degree of total dynamic recrystallization remains small as this mechanism competes to a large extend with nucleation at grain boundaries $[7,14]$. In addition, the twin-aided dynamic recrystallization (TDRX) is another mechanism known to occur during deformation of magnesium alloys $[2,15,16]$. Twinned regions exhibit a higher amount of local stresses. Consequently, the twin boundaries can act as nucleation sites for dynamic recrystallization $[17,18]$. The TDRX mechanism essentially comprises three elementary processes: nucleation, conversion of small angle grain boundaries into regular grain boundaries and local grain boundary motion. An increased dislocation density within the twins and the twin boundaries accompanies this mechanism. TDRX is particularly common in contraction twins with a higher dislocation density. The rotation of grains during twinning leads to the activation of additional slip systems besides the basal sliding. Some grains nucleate by the mutual crossing of 
twins for the formation of double twins. Finally, the LAGB developed in twins grow to HAGB [15,19]. During hot deformation large amounts of dynamically recrystallized grains develop. Dynamic recrystallization models are used to predict the recrystallized volume fraction and the size of DRX grains. The most important approaches to describe the kinetics of primary recrystallization were developed independently by Johnson, Mehl, Avrami and Kolmogorow (JMAK theory). The basic assumptions of this theory are on the one hand the existence of a statistical distribution of nucleation sites in the volume. On the other hand, an isotropic growth of recrystallization nuclei at a constant growth rate is assumed. Furthermore, for the time-dependent description of the recrystallized volume fraction a repeated nucleation within the recrystallized volume is excluded [20-22]. In this study, twin roll cast strip of the Mg-2Zn-1Al-0.3Ca (ZAX210) magnesium alloy after annealing represents the initial material. The dynamic recrystallization behaviour of the annealed ZAX210 alloy during plane strain compression tests at various temperatures and strain rates was investigated. The knowledge of the complex structural change during hot deformation is essential for reliable simulation and the understanding of recrystallization mechanisms. Based on the JMAK theory, the microstructural changes during hot deformation are presented in this paper.

\section{MATERIALS AND METHODS}

Ingots of the ZAX210 alloy were melted under protective gas atmosphere and the melt was supplied to a twin roll casting pilot plant at the Institute of Metal Forming of the Technische Universität Bergakademie Freiberg. Strips with a thickness of $5.3 \mathrm{~mm}$ and a width of $730 \mathrm{~mm}$ were produced via continuous twin roll casting. Details of the twin roll casting process as well as the resulting microstructure can be found in [23]. After twin roll casting the strips were annealed at a temperature of $420^{\circ} \mathrm{C}$ and a holding time of two hours in order to establish a homogenous microstructure with equiaxial grains. The chemical composition of the ZAX210 alloy is summarized in Table 1. Directly after annealing, plane strain compression tests at deformation temperatures of $250{ }^{\circ} \mathrm{C}, 350{ }^{\circ} \mathrm{C}$ and $450^{\circ} \mathrm{C}$ and strain rates of $0.1 \mathrm{~s}^{-1}, 1 \mathrm{~s}^{-1}, 5 \mathrm{~s}^{-1}$ and $10 \mathrm{~s}^{-1}$ were performed to an equivalent logarithmic strain of $\varphi=0.3,0.4,0.5,0.6$ and 1. Details of the experimental procedure of the plane strain compression tests are summarized in [23].

Table 1 Chemical composition of the ZAX210 alloy (wt\%) determined via spark emission spectroscopy

\begin{tabular}{|c|c|c|c|c|c|c|c|}
\hline $\mathbf{Z n}$ & $\mathbf{A l}$ & $\mathbf{C a}$ & $\mathrm{Cu}$ & $\mathbf{F e}$ & $\mathbf{N i}$ & Others & $\mathbf{M g}$ \\
\hline 2.29 & 0.92 & $<0.25$ & 0.001 & 0.005 & 0.001 & $<0.05$ & Balance \\
\hline
\end{tabular}

Immediately after the compression tests, the samples were quenched in water to freeze the microstructure and impede temperature-controlled processes, such as diffusion, recovery or static recrystallization. Samples were cut in the middle and were prepared metallographically for optical microscopy. Due to the inhomogeneous strain distribution over the cross-section of the sample, the area referring to the equivalent logarithmic strain was selected for microstructural characterization. The dynamic recrystallization behaviour was described using the Kocks-Mecking plot [24,25] of each flow curve. Here, the hardening rate was calculated from the slopes of the discrete values of the flow curves and plotted over the flow stress. Based on characteristic points of the Kocks-Mecking plot the critical strain for the start of DRX can be determined. More details can be found in [26].

\section{RESULTS AND DISCUSSION}

\subsection{Microstructure of twin roll cast and annealed samples}

The initial microstructure, mentioned as twin roll cast and annealed condition is shown in Figure 1. After annealing the microstructure exhibits equiaxial grains (Figure 1a) with an average grain size of approximately $20 \mu \mathrm{m}$. The grain size distribution is shown in Figure 1b. As can be seen from the -optical micrograph a few 
coarse grains with a maximum grain size of about $55 \mu \mathrm{m}$ occur in the mid-thickness of the strip. Further details of the influence of different temperature-time-regimes during heat treatment of ZAX210 are presented in [23].
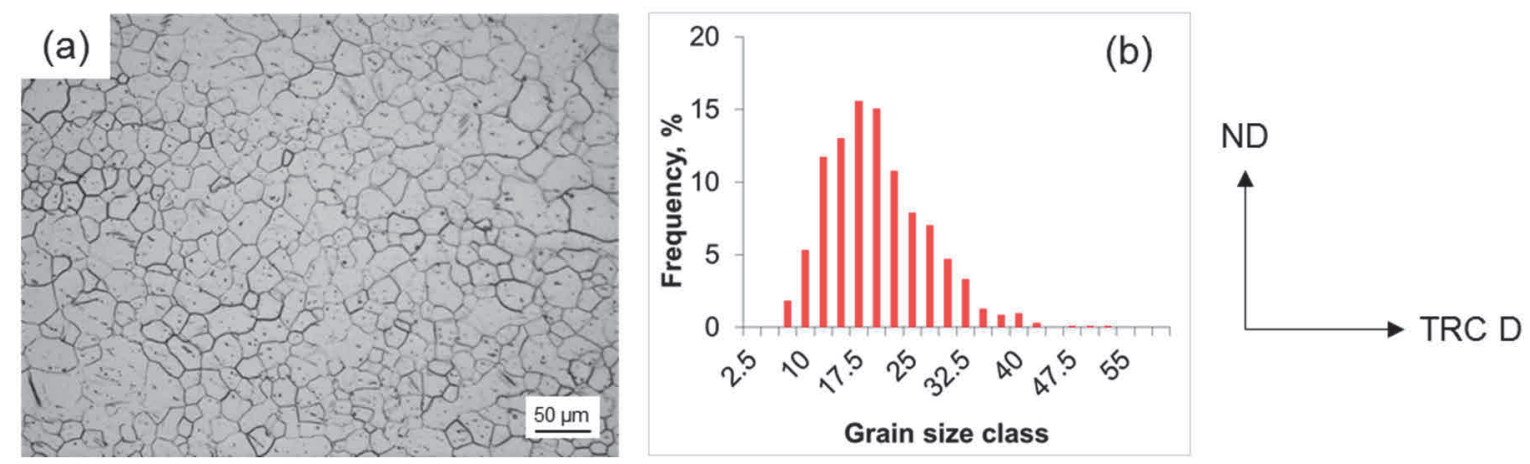

Figure 1 (a) Microstructure of the twin roll cast and annealed ZAX210 alloy and (b) grain size distribution

\subsection{Compression behaviour and microstructure evolution}

\section{Flow stress behaviour}

Exemplary flow curves during plane strain compression at temperatures of $250{ }^{\circ} \mathrm{C}, 350^{\circ} \mathrm{C}$ and $450^{\circ} \mathrm{C}$ as well as strain rates of $0.1 \mathrm{~s}^{-1}, 1 \mathrm{~s}^{-1}$ and $10 \mathrm{~s}^{-1}$ are shown in Figure 2. Strain hardening at the beginning of the compression deformation results in an increase of the flow stress. The maximum flow stress is temperature and strain rate dependent. However, the maximum flow stress is shifted to higher equivalent logarithmic strains when temperature decreases. It behaves contrary, when the strain rate is increased from $1 \mathrm{~s}^{-1}$ to $10 \mathrm{~s}^{-1}$. After reaching the maximum flow stress and with further deformation the flow curves decline as a result of softening processes, likely dynamic recrystallization. More detailed description of the flow stress behaviour of the ZAX210 alloy can be found in [23].
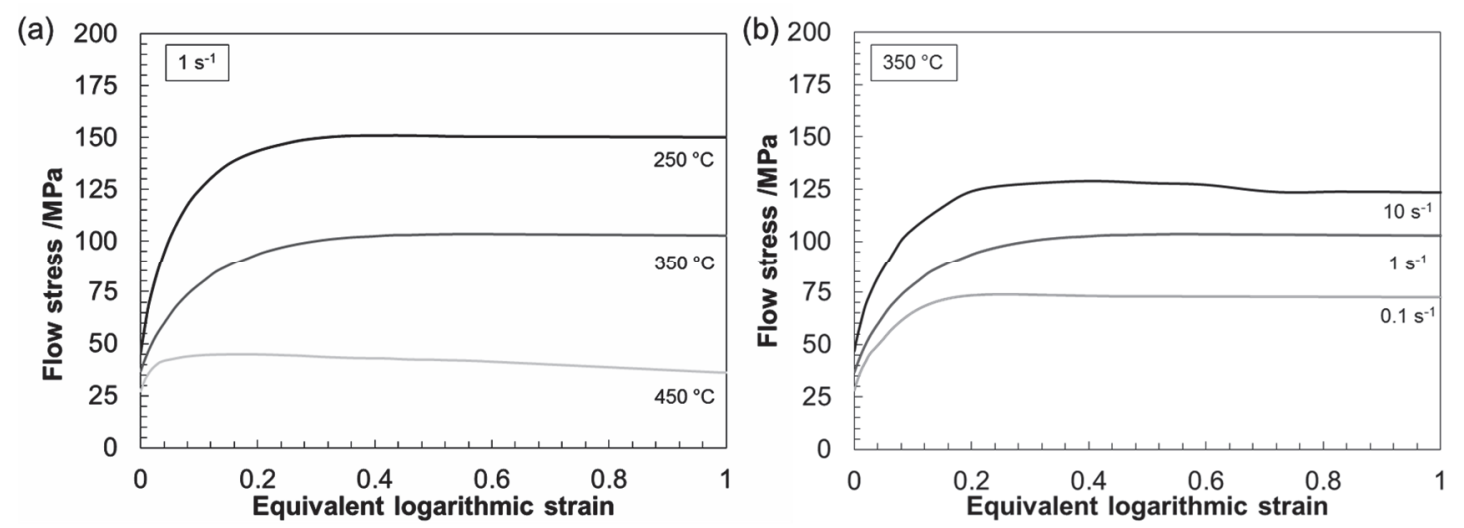

Figure 2 Flow curves of twin roll cast and annealed ZAX210 alloy in dependence of (a) temperature (at a strain rate of $1 \mathrm{~s}^{-1}$ ) and (b) strain rate (at a temperature of $350^{\circ} \mathrm{C}$ )

\section{Effect of temperature on microstructure}

Optical micrographs of the ZAX210 alloy after compression at a strain rate of $1 \mathrm{~s}^{-1}$, an equivalent logarithmic strain of 0.6 and deformation temperatures of $250{ }^{\circ} \mathrm{C}, 350^{\circ} \mathrm{C}$ and $450^{\circ} \mathrm{C}$ are shown in Figure 3. As can be seen, the increase in temperature promotes dynamic recrystallization processes. The dynamically recrystallized fraction increases from $7.4 \%\left(250{ }^{\circ} \mathrm{C}\right)$ to $18.4 \%\left(350{ }^{\circ} \mathrm{C}\right)$ and finally to $\approx 100 \%\left(450{ }^{\circ} \mathrm{C}\right)$, while the grain size of DRX grains increases, too. At temperatures of $250^{\circ} \mathrm{C}$, areas of small grains $(<2 \mu \mathrm{m})$ occur surrounded by the deformed microstructure. At $350{ }^{\circ} \mathrm{C}$, the size of the recrystallized grains increases to $\approx 5 \mu \mathrm{m}$. A further increase in temperature to $450{ }^{\circ} \mathrm{C}$ leads to abnormal grain growth $(\approx 30 \mu \mathrm{m})$. 


\section{ME' ${ }^{\prime} \mathbf{T L}^{\circ}$
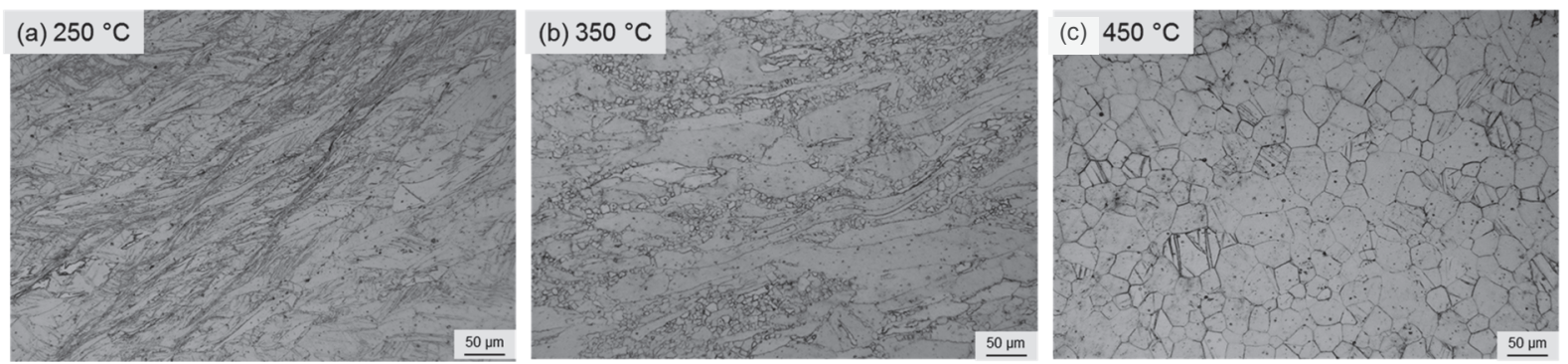

Figure 3 Microstructure of the ZAX210 alloy after compression at strain rate of $1 \mathrm{~s}^{-1}$, an equivalent logarithmic strain of 0.6 and deformation temperatures (a) $250{ }^{\circ} \mathrm{C}$, (b) $350^{\circ} \mathrm{C}$ and (c) $450{ }^{\circ} \mathrm{C}$

\section{Effect of strain rate on microstructure}

The effect of the strain rate on the microstructural evolution of the twin roll cast and annealed ZAX210 alloy is exemplarily shown by optical micrographs in Figure 4 for a deformation temperature of $350{ }^{\circ} \mathrm{C}$. Increasing the strain rate, results in a higher dynamically recrystallized fraction. Especially, when the strain rate was increased from $1 \mathrm{~s}^{-1}$ to $10 \mathrm{~s}^{-1}$ the fraction of DRX grains rose from $18.4 \%$ to $38.8 \%$. However, the size of the DRX grains at about $\approx 5 \mu \mathrm{m}$ remains practically the same.
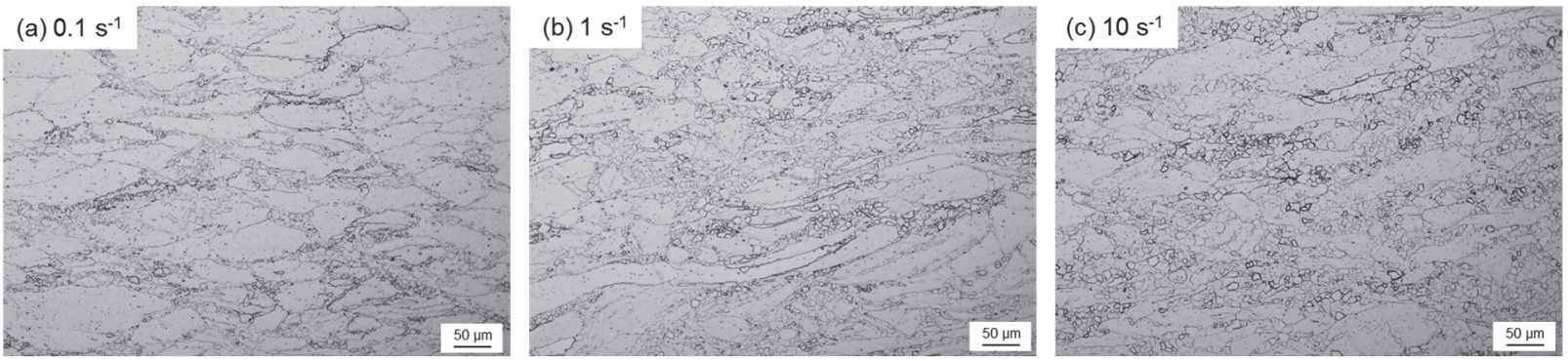

Figure 4 Microstructure of the ZAX210 alloy after compression at $350^{\circ} \mathrm{C}$, an equivalent logarithmic strain of 0.6 and strain rates of (a) $0.1 \mathrm{~s}^{-1}$, (b) $1 \mathrm{~s}^{-1}$ and (c) $10 \mathrm{~s}^{-1}$

\section{3. $\quad$ DRX modelling}

For the determination of the model coefficients (Table 2) it is assumed that the processes occurring during hot deformation are diffusion controlled and therefore temperature and strain rate dependent. This relation is described through the Zener-Hollomon parameter $Z$ (Equation 1). The determined relationship has validity for deformation temperatures from $250^{\circ} \mathrm{C}$ to $450{ }^{\circ} \mathrm{C}$ at strain rates from $0.1 \mathrm{~s}^{-1}$ to $10 \mathrm{~s}^{-1}$ and was calculated with a coefficient of determination of $r^{2}=0.96$ ( $D_{0}$ is an initial grain size)

Table 2 Models used to describe the dynamic recrystallization behaviour

\begin{tabular}{lc}
\hline \hline Zener-Hollomon parameter & $Z=\dot{\varphi} \cdot \exp \left(\frac{155133}{R \cdot T}\right)$ \\
critical logarithmic strain & $\varphi_{c}=0.0079 \cdot D_{0}^{0.0657} \cdot Z^{0.0897}$ \\
$\begin{array}{l}\text { equivalent logarithmic strain for } 50 \% \\
\text { recrystallized fraction }\end{array}$ & $\varphi_{0.5}=0.0269 \cdot D_{0}^{0.464} \cdot \exp \left(\frac{729.72}{T}\right) \cdot \dot{\varphi}^{0.0324}$ \\
dynamically recrystallized fraction & $X_{d y n}=1-\exp \left[-0.704\left(\frac{\varphi-\varphi_{c}}{\varphi_{0.5}-\varphi_{c}}\right)^{2.144}\right]$ \\
dynamically recrystallized grain size & $D_{d y n}=55963.6 \cdot Z^{0.3062}$
\end{tabular}


The critical strain $\varphi_{c}$ (Equation 2) decreases with rising temperature or falling strain rate. Even at temperatures of $250{ }^{\circ} \mathrm{C}$ DRX starts above a critical strain of 0.2 . Increasing temperatures accelerate DRX and induce its beginning at an equivalent logarithmic strain of 0.12 . For the twin roll cast and annealed ZAX210 alloy with an initial grain size of about $20 \mu \mathrm{m}$ the critical strain ranges from 0.12 to 0.27 for the examined forming conditions. The equivalent logarithmic strain for $50 \%$ recrystallized fraction $\varphi_{0.5}$ was calculated using Equation 3 . Increasing deformation temperature and/or strain rate is associated with attaining $50 \%$ recrystallized fraction at lower equivalent logarithmic strains (Figure 5). At temperatures of $250{ }^{\circ} \mathrm{C}$ and a strain rate of $1 \mathrm{~s}^{-1} 50 \%$ DRX fraction is observed at an equivalent logarithmic strain of 1.6 , while at $350^{\circ} \mathrm{C}$ it is 0.9 . For high strain rates $\left(10 \mathrm{~s}^{-1}\right) \varphi 0.5$ ranges from $1.3\left(250^{\circ} \mathrm{C}\right)$ to $0.7\left(350^{\circ} \mathrm{C}\right)$ and $0.4\left(450^{\circ} \mathrm{C}\right)$.
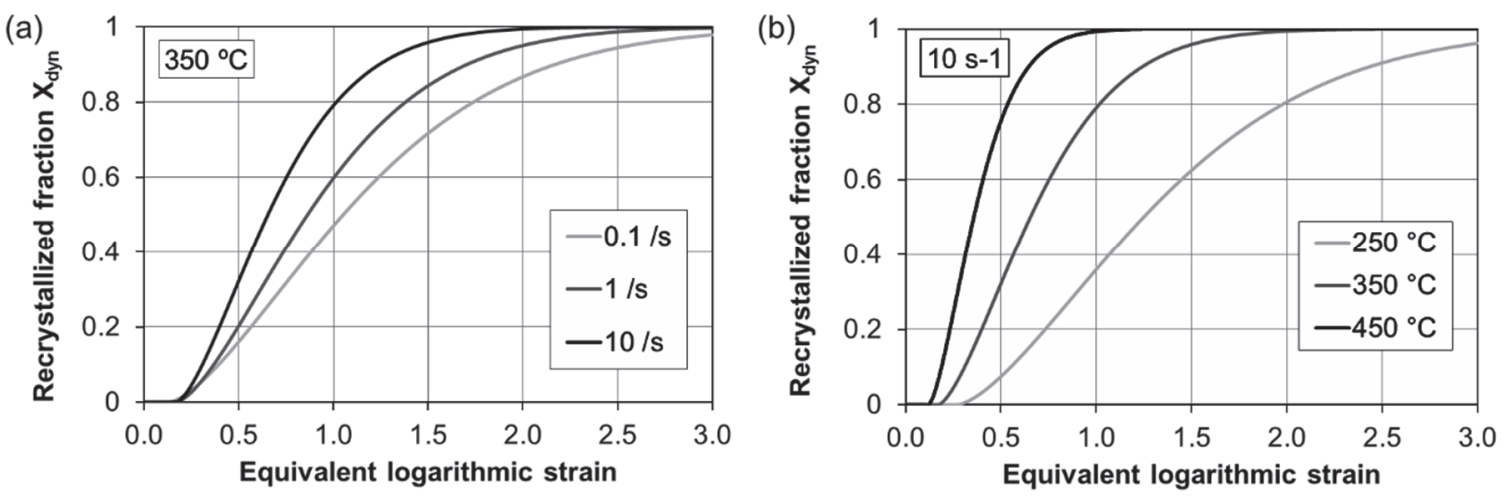

Figure 5 Recrystallized fraction $X_{\text {dyn }}$ in dependence of (a) strain rate at deformation temperature $350{ }^{\circ} \mathrm{C}$ and (b) temperature at a strain rate of $10 \mathrm{~s}^{-1}$

\section{DISCUSSION}

At low deformation temperatures $\left(250^{\circ} \mathrm{C}\right)$, regroupment of dislocations hardly occurs. Consequently other deformation mechanism, such as twinning, are more important. Rising deformation temperatures lead to pronounced DRX as a result of dislocation climb and slip as well as the activation of non-basal slip at elevated temperatures. At higher deformation temperatures $\left(450^{\circ} \mathrm{C}\right)$, significant grain growth of the recrystallized grains is observed due to higher mobility of the grain boundaries. The optical micrographs of Figure 4 reveal a strong dependence of the microstructural evolution and the resulting recrystallization mechanism on the strain rate. Dynamic recrystallization is induced by the accumulation of dislocations, which results in high local misorientations, for example along grain boundaries. At low strain rates $\left(\leq 1 \mathrm{~s}^{-1}\right)$ new fine grains developed along the grain boundaries of the original microstructure forming a necklace structure. With increasing strain rate $\left(10 \mathrm{~s}^{-1}\right)$ a more homogenous microstructure is observed due to a pronounced dynamic recrystallization. New grains are predominantly formed along grain and twin boundaries. Thus, the recrystallization mechanism seems to change when increasing strain rate. Yan et al. [27] show similar results after compression of ZK40 alloy at high strain rates. The authors assume, that the formation of twins accommodate the deformation process because at high deformation rates dislocation motion is restricted. This effect was also reported by Ishikawa et al. [28]. Twin-aided dynamic recrystallization (TDRX) was observed during deformation of magnesium alloys before $[2,15,16]$. Further investigations are required in order to clarify, which kind of twins occur during deformation of the ZAX210 alloy and if they are responsible for this strain-dependent deformation behaviour.

\section{CONCLUSION}

The dynamic recrystallization behaviour of the twin roll cast and annealed ZAX210 alloy during hot plane strain compression tests at various temperatures and strain rates was investigated. At lower strain rates $\left(\leq 1 \mathrm{~s}^{-1}\right)$ 
$\mathrm{DRX}$ at grain boundaries of the original microstructure was the dominant softening mechanism. New fine grains form a necklace structure. Increasing strain rate $\left(10 \mathrm{~s}^{-1}\right)$ accelerates recrystallization and new grains mainly develop at grain and twin boundaries. It is assumed, that twin-aided recrystallization is responsible for DRX at high strain rates.

\section{ACKNOWLEDGEMENTS}

\section{This research was funded by the Federal Ministry of Education and Research Germany within the research project "SubSEEMag".}

\section{REFERENCES}

[1] JARDIM, Paula M., SOLÓRZANO, Guillermo and SANDE, John B. V. Precipitate crystal structure determination in melt spun Mg-1.5wt\%Ca-6wt\%Zn alloy. Microscopy and microanalysis the official journal of Microscopy Society of America, Microbeam Analysis Society, Microscopical Society of Canada. 2002. vol. 8, pp. 487-496.

[2] XU, S. W., OH-ISHI, K., KAMADO, S. and HOMMA, T. Twins, recrystallization and texture evolution of a Mg5.99Zn-1.76Ca-0.35Mn (wt\%) alloy during indirect extrusion process. Scripta Materialia. 2011. vol. 65, pp. 875878.

[3] HRADILOVA, M. and LEJCEK, P. Dynamic recrystallization during hot deformation of Mg-Zn-Ca. In METAL 2013: 22th International Conference on Metallurgy and Materials. Ostrava: TANGER, 2013, pp. 1266-1271.

[4] DU, Y. Z., ZHENG, M. Y., QIAO, X. G., WU, K., LIU, X. D., WANG, G. J., LV, X. Y., LI, M. J., LIU, X. L., WANG, Z. $\mathrm{J}$. and LIU, Y. T. The effect of double extrusion on the microstructure and mechanical properties of $\mathrm{Mg}-\mathrm{Zn}-\mathrm{Ca}$ alloy. In 14th International Conference on the Strength of Materials. 2013. vol. 583, pp. 69-77.

[5] GENG, J. and NIE, J. F. Microstructure and mechanical properties of extruded Mg-1Ca-1Zn-0.6Zr alloy. Materials Science and Engineering A. 2016. vol. 653, pp. 27-34.

[6] ZHANG, Baoping, WANG, Yin, GENG and Lin, LU, Chunxiang. Effects of calcium on texture and mechanical properties of hot-extruded Mg-Zn-Ca alloys. Materials Science and Engineering A. 2012. vol. 539, pp. 56-60.

[7] ROBSON, Joseph D., HENRY, D. T. and DAVIS, Bruce. Particle effects on recrystallization in magnesiummanganese alloys: Particle-stimulated nucleation. Acta Mater. 2009. vol. 57, pp. 2739-2747.

[8] LIU, Z.-m., XING, Shuming, BAO, Pei W., LI, N., YAO, S.-Q. and ZHANG, M. Characteristics of hot tensile deformation and microstructure evolution of twin-roll cast AZ31B magnesium alloys. Trans. Nonferr. Met. Soc. 2010. vol. 20, pp. 776-782.

[9] PENG, Wei P., LI, P. J., ZENG, P. and LEI, L. P. Hot deformation behavior and microstructure evolution of twinroll-cast Mg-2.9Al-0.9Zn alloy: A study with processing map. Mater. Sci. Eng. A, 2008. vol. 494, pp. 173-178.

[10] PÉREZ-PRADO, M. T., del Valle, J. A., CONTRERAS, J. M. and RUANO, O. A. Microstructural evolution during large strain hot rolling of an AM60 Mg alloy. Scripta Materialia. 2004. vol. 50, pp. 661-665.

[11] COURET, A., CAILLARD, D. An in situ study of prismatic glide in magnesium-I. The rate controlling mechanism. Acta Metallurgica. 1985. vol. 33, pp. 1447-1454.

[12] DOHERTY, Roger D., HUGHES, D. A., HUMPHREYS, F. J., JONAS, John J., JUUL JENSEN, D., KASSNER, M. E., KING, W. E., MCNELLEY, T. R., MCQUEEN, H. J. and ROLLETT, A. D. Current issues in recrystallization: A review. Materials Today. 1998. vol. 1, pp. 14-15.

[13] HUMPHREYS, F. J. Nucleation in recrystallization. Mater. Sci. Forum. 2004. vol. 467-470, pp. 107-116.

[14] MACKENZIE, L. W. F., LORIMER, GORDON W., HUMPHREYS, F. J. and WILKS, Tim. Recrystallization behaviour of two magnesium alloys. Mater. Sci. Forum. 2004. vol. 467-470, pp. 477-482.

[15] XU, S. W., KAMADO, S., MATSUMOTO, N., HONMA, T. and KOJIMA, Y. Recrystallization mechanism of as-cast AZ91 magnesium alloy during hot compressive deformation. Materials Science and Engineering A. 2009. vol. 527, pp. 52-60.

[16] AL-SAMMAN, Talal, MOLODOV, Konstantin D., MOLODOV, Dmitri A., GOTTSTEIN, Günter and SUWAS, Satyam. Softening and dynamic recrystallization in magnesium single crystals during c-axis compression. Acta Mater. 2012. vol. 60, pp. 537-545. 
[17] LIANG, S., OKRUTNY, P., WANG, X. and ZUROB, H. S. Recrystalliaztion nucleation sites in deformed AZ31, In Mg2012: 9th International Conference on Magnesium Alloys and their Applications. 2012. vol. 9, pp. 663-668.

[18] AL-SAMMAN, T. and GOTTSTEIN, G. Dynamic recrystallization during high temperature deformation of magnesium. Materials Science and Engineering A. 2008. vol. 490, pp. 411-420.

[19] JIANG, L., JONAS, J. J., MISHRA, R. K., LUO, A. A., SACHDEV, A. K. and GODET, S. Twinning and texture development in two Mg alloys subjected to loading along three different strain paths. Acta Mater. 2007. vol. 55, pp. 3899-3910.

[20] AVRAMI, M. Kinetics of phase change. I - General theory. Journal of Chemical Physics. 1939. vol. 7, pp. 11031112.

[21] KOLMOGOROV, A. Statistical theory of crystallization of metals. Bull. Acad. Sci. USSR Ser. Math., 1937. pp. 355-359. (in Russian)

[22] JOHNSON, W. A. and MEHL, R. F. Reaction kinetics in processes of nucleation and growth. Transactions of the AIME. 1939, pp. 416-458.

[23] KITTNER, Kristina, ULLMANN, Madlen, HENSELER, Thorsten, KAWALLA, Rudolf and PRAHL, Ulrich. Microstructure and hot deformation behavior of twin roll cast Mg-2Zn-1Al-0.3Ca alloy. Materials. 2019. vol. 12, pp. 1020.

[24] MECKING, H. and KOCKS, U. F. A mechanism for static and dynamic recovery. Strength of Metals and Alloys. Eds. Haasen et al. Pergamon. 1979. pp. 345-350.

[25] MECKING, H. and GOTTSTEIN, G. Recrystallization of Metallic Materials. Riederer Verlag, Stuttgart. 1978.

[26] ULLMANN, Madlen, SCHMIDTCHEN, Matthias and KAWALLA, Rudolf. Dynamic recrystallization behaviour of twin roll cast AZ31 strips during hot deformation. KEM. 2014. vol. 622-623, pp. 569-574.

[27] YAN, H.-G., WU, Y.-Z., CHEN, J.-H., ZHU, S.-Q., LIU, Z.-W. and TIAN, J. Microstructure evolution of ZK40 magnesium alloy during high strain rate compression deformation at elevated temperatures. Materials Science and Technology. 2011. vol. 27, pp. 1416-1421.

[28] ISHIKAWA, Koichi, WATANABE, Hiroyuki and MUKAI, Toshiji. High strain rate deformation behavior of an AZ91 magnesium alloy at elevated temperatures. Materials Letters. 2005. vol. 59, pp. 1511-1515. 